\title{
Effect of Short-Term Aging Process on the Moisture Susceptibility of Asphalt Mixtures and Binders Containing Sasobit Warm Mix Additive
}

\author{
Bo Li, ${ }^{1,2,3}$ Jinyu Yang, ${ }^{1,3}$ Xiaohui Li, ${ }^{1}$ Xiang Liu, ${ }^{1,2}$ Feng Han, ${ }^{1}$ and Liangying Li $^{1}$ \\ ${ }^{1}$ Key Laboratory of Road \& Bridge and Underground Engineering of Gansu Province, Lanzhou Jiaotong University, \\ Lanzhou, Gansu 730070, China \\ ${ }^{2}$ Key Laboratory of Road Structure and Material of Ministry of Transport, Chang'an University, Xian, Shaanxi 710064, China \\ ${ }^{3}$ Key Laboratory of Highway Network Monitoring of Gansu Province, Gansu Hengda Road and Bridge Engineering Group Co. Ltd., \\ Lanzhou, Gansu 730070, China
}

Correspondence should be addressed to Bo Li; libolzjtu@hotmail.com

Received 23 July 2015; Revised 20 October 2015; Accepted 16 November 2015

Academic Editor: Charles C. Sorrell

Copyright (C) $2015 \mathrm{Bo} \mathrm{Li}$ et al. This is an open access article distributed under the Creative Commons Attribution License, which permits unrestricted use, distribution, and reproduction in any medium, provided the original work is properly cited.

\begin{abstract}
Moisture susceptibility is one of the key issues of warm mix asphalt (WMA). In this research, the moisture susceptibility of asphalt mixtures and binders containing Sasobit warm mix additive was investigated in comparison to that of hot mixture asphalt (HMA) through laboratory aging experiments. The WMA asphalt mixtures were aged in the laboratory at three aging temperatures and times. The moisture susceptibility of the asphalt mixtures was measured through the laboratory immersed Marshall test and freezethaw splitting test. The surface free energy (SFE) of asphalt binders extracted from WMA asphalt mixtures was determined by the sessile drop method. The results show that the aging time and temperature have a significant effect on the improvement in moisture susceptibility in terms of both the freeze-thaw splitting strength ratios and the residual Marshall stability of asphalt mixtures containing Sasobit warm mix additive. The SFE of asphalt binders extracted from Sasobit warm mix increased with the aging time and temperature. The moisture susceptibility of the asphalt mixtures and binders containing Sasobit warm mixes was similar to or even greater than that of HMA aging under certain conditions.
\end{abstract}

\section{Introduction}

The warm mix asphalt (WMA) technology, which was developed in Europe, is now attracting considerable interest globally. It allows for mixing, transporting, and paving process to be carried out at significantly lower temperatures, as a result of lowered viscosity of the asphalt binder and/or increased workability of the mixture using minimal heat. The technology was developed primarily to address issues such as high vapor emissions and high energy costs associated with the traditional hot mix asphalt (HMA) paving. It thus exhibits good potential as a replacement to conventional HMA. Despite such benefits, including reduced emissions and fuel usage, the feasibility of replacing HMA pavements with WMA is yet to be clarified through field and laboratory evaluations. One of the major concerns in WMA usage is the susceptibility to moisture-induced damage [1].
About fifteen different WMA technologies are currently available, of which three are also globally available: Sasobit, Evotherm, and WMA Foam [2]. This paper presents the evaluation of one such additive, namely, branded Sasobit, which is a product of Sasol Wax. It is a fine crystalline, longchain aliphatic polymethylene hydrocarbon produced from coal gasification using the Fischer-Tropsch (FT) process. Hurley and Prowell [3] found that Sasobit improves the compactability of mixtures at temperatures as low as $88^{\circ} \mathrm{C}$. The addition of Sasobit does not affect the resilient modulus or rutting potential of an asphalt mix. However, the lower compaction temperature used when producing warm asphalt with Sasobit or any such similar warm mix additive may increase the potential for moisture damage. Since WMA containing Sasobit is becoming a popular paving technology, many researchers and transportation personnel are interested in its moisture resistance. 
Liu et al. [4] found that Sasobit-modified WMA had insignificant effects on the moisture susceptibility though it reduced mixing and compaction temperatures, in line with a field experimental feature project. Guo [5] found that the long-term water stability of Sasobit-asphalt mixture was expectedly poor owing to the lower compaction temperature. Ji et al. [6] also found that a Sasobit-asphalt mixture had lower moisture stability, but the reduction was insignificant. However, Zhang and Huang [7] and Ji and sun [8] found that the water stability of Sasobit mixtures was almost at the same level as that of HMA. Buddhala et al. [9] found that the maximum and average decrease in the free energy of reduction were $20.5 \%$ and $13.2 \%$, respectively, for an asphalt binder with 3\% Sasobit. Using the surface free energy (SFE) method, Wasiuddin et al. [10] observed that Sasobit increases the wettability of asphalt binders over aggregates and reduces the adhesion (free energy of adhesion) between asphalt binders and aggregates. Ghabchi et al. [11] reported that Sasobit could reduce the moisture susceptibility potential of the mixes through a mechanistic framework (i.e., SFE). Thus, there are different conclusions on the moisture susceptibility of asphalt mixtures and binders containing Sasobit warm mix additive.

Recently, the research conducted in NCHRP Project 949 , based on a limited number of field projects, showed that the use of WMA that did not undergo a summer of aging prior to multiple freeze-thaw cycles or wet and cold days in the first winter should be approached with caution, especially in extreme climates, owing to moisture susceptibility [12]. Gandhi et al. [13] found that WMA additives did not seem to have any significant effect on the moisture susceptibility of the mixes as they aged but significantly increased the resilient modulus values of the mixes as they aged. Zelelew et al. [14] found that plant-produced WMA mixtures exhibited increased resistance to moisture damage, as shown by laboratory evaluations of the mechanical properties of WMA. Sargand et al. [15] conducted laboratory tests on core samples and found that WMA mixtures had higher indirect tensile strength compared to HMA mixtures, after 3 months of service. Mogawer et al. [16] found that the moisture resistances of WMA mixtures improved significantly with an increase in aging time or temperature, by using the Hamburg wheeltracking device (HWTD). Mixtures aged at longer times and at higher aging temperatures exhibited the best performance. It can thus be concluded that the moisture susceptibility evaluation experiment of WMA should be investigated and modified in the laboratory. Further, short-term aging should be included in the moisture susceptibility experiment in order to evaluate objectively the moisture susceptibility of WMA.

The main objective of this research is to gain an improved understanding of the moisture susceptibility of WMA. To investigate the effect of short-term aging on the moisture susceptibility of asphalt mixtures containing Sasobit warm mix additive, the moisture susceptibility of WMA mixture was measured through the immersed Marshall test and freeze-thaw splitting test in the laboratory. The SFE of asphalt binders was also determined by the sessile drop method to evaluate the influence of short-term aging on the asphalt binder extracted from the WMA mixture.

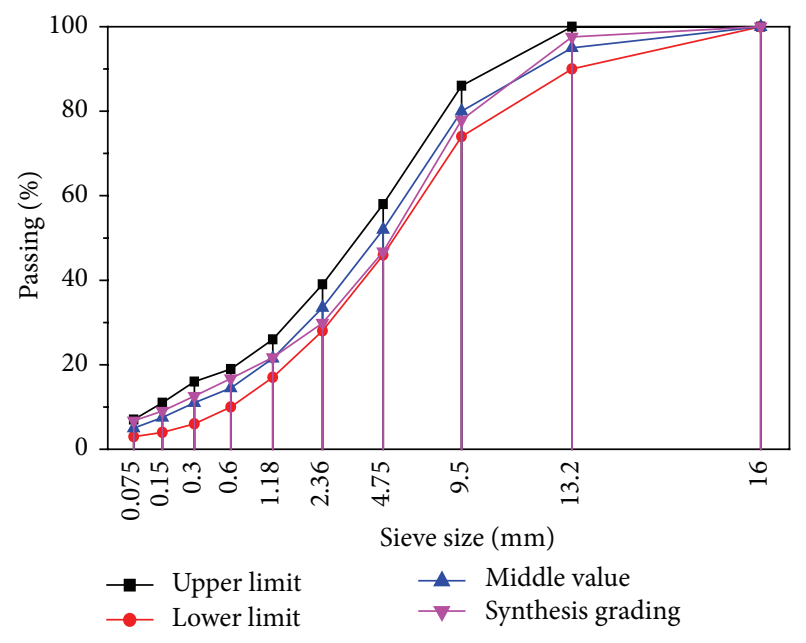

FIgURE 1: Mixture gradations.

\section{Materials and Methods}

2.1. Materials. One binder (90\# A) was used, and warm asphalt was prepared by adding Sasobit to the virgin binders for preparing the samples in this study. Table 1 lists the properties of the virgin binders.

Sasobit is long-chain aliphatic wax (chain lengths of 40115 carbon atoms) obtained from coal gasification using the Fischer-Tropsch process. Sasobit melts in the asphalt binder at temperatures of $85-115^{\circ} \mathrm{C}$, causing a marked reduction in the viscosity of the binder. The manufacturer reports a reduction of $10-30^{\circ} \mathrm{C}$ in the mixing and handling temperatures. Sasobit loading concentrations of $3 \mathrm{wt} \%$ were selected for this study because this is typically the maximum loading concentration, above which the low temperature performance of Sasobit-modified WMA would be negatively affected [17]. The manufacturer of Sasobit, Sasol, also recommends a Sasobit concentration larger than $0.8 \%$, but no more than $3 \%$. Sasobit-modified asphalt binders were prepared by heating asphalt to $150^{\circ} \mathrm{C}$, followed by the addition of preweighed Sasobit and gentle stirring for approximately $1 \mathrm{~h}$ to achieve a homogenous blend.

The aggregates used in this study were obtained from one source (designated as lime). The aggregates were tested for gradation as the ASTM C136. Asphalt concrete (AC) mixture with a nominal maximum size of $16 \mathrm{~mm}$ was used for the mix design in this experiment. Gradations of the AC-16 mixtures are illustrated in Figure 1.

2.2. Test Procedures. Figure 2 illustrates the flowchart of the experimental design used in this laboratory investigation.

In this study, a conventional HMA mixture composed of new virgin binder and aggregate is used as a control. The procedures described in JTG E40-2011 (Standard Test Methods of Bitumen and Bituminous Mixtures for Highway Engineering) were followed for the preparation of HMA and WMA specimens. The compacted temperature was $150^{\circ} \mathrm{C}$ and $125^{\circ} \mathrm{C}$ for HMA and all WMA specimens, including short-term aging and no aging specimens, respectively. In the present study, the Marshall system was used to obtain 
TABLE 1: Properties of the three asphalt binders.

\begin{tabular}{|c|c|c|c|c|c|}
\hline Penetration & Ductility & Softening noint ${ }^{\circ} \mathrm{C}$ & & Residue after RTFOT & \\
\hline$\left(100 \mathrm{~g}, 5 \mathrm{~s}, 25^{\circ} \mathrm{C}\right) / 0.1 \mathrm{~mm}$ & $\left(15^{\circ} \mathrm{C}\right) / \mathrm{cm}$ & sortening point/ C & Mass loss & Penetration ratio of $25^{\circ} \mathrm{C} / \%$ & Ductility $\left(10^{\circ} \mathrm{C}\right) / \mathrm{cm}$ \\
\hline 85.5 & $>100$ & 45.6 & 0.06 & 70 & 9.0 \\
\hline
\end{tabular}

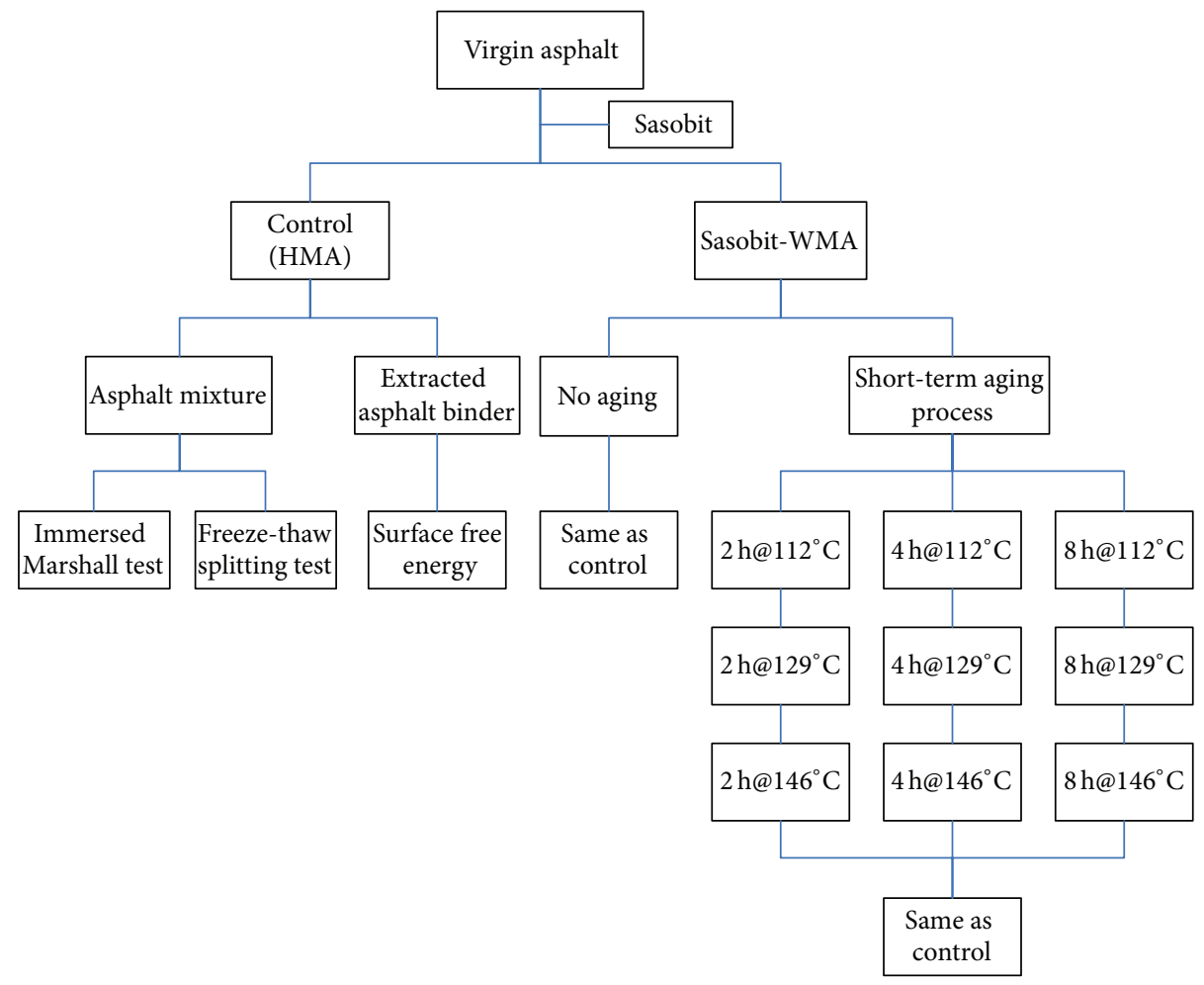

FIGURE 2: Flowchart of experimental design procedure.

the optimum asphalt contents (OAC) for all mixtures. The OAC of HMA was $4.73 \%$, which satisfies the requirements specified in JTG F40-2004 F40 (Technical Specification for Construction of Highway Asphalt Pavement).

Nine different short-term oven conditioning protocols were selected for the loosed WMA mixture specimens prior to compaction, which include 3 aging times $(2 \mathrm{~h}, 4 \mathrm{~h}$, and $8 \mathrm{~h})$ and 3 aging temperatures $\left(112^{\circ} \mathrm{C}, 129^{\circ} \mathrm{C}\right.$, and $\left.146^{\circ} \mathrm{C}\right)$. For loosed WMA mixture specimens, the aging time of $2 \mathrm{~h}$ at compaction temperature was used, as proposed by the recently completed NCHRP Project 9-43, and $4 \mathrm{~h}$ at compaction temperature was proposed because it is the current standard in USA. The aging time of $8 \mathrm{~h}$ was used to investigate the effect of a longer aging time on the WMA mixtures and binders. The other protocols used were derived by combining common aging temperatures and times.

In this research, the aged asphalt was extracted from all the used mixtures based on the ASTM D2172 procedure, by using a centrifuge extractor with trichloroethylene (THF) as the solvent. The specified quantity of the asphalt mixture was randomly collected from the HMA and WMA specimens after the short-term aging process and was dissolved into THF in a centrifuge extractor. The extract was passed through a filter system to remove the fine particles, and the extract was finally distilled to remove the solvent from the asphalt binder.
The moisture susceptibility of the asphalt mixture was also measured through the laboratory immersed Marshall test and freeze-thaw splitting test. In the immersed Marshall test, two groups of duplicate specimens (three specimens for each group, $101.6 \mathrm{~mm}$ in diameter and $63.5 \pm 1.3 \mathrm{~mm}$ in height) were prepared. The first group of the specimens was submerged in a water bath at $60^{\circ} \mathrm{C}$ for $30 \mathrm{~min}$, and the second group of the specimens was submerged in the bath at $60^{\circ} \mathrm{C}$ for $48 \mathrm{~h}$. Consequently, the residual Marshall stability is determined as follows:

$$
\mathrm{MS}_{0}=\frac{\mathrm{MS}_{2}}{\mathrm{MS}_{1}} \times 100 \%,
$$

where $\mathrm{MS}_{2}$ is the Marshall stability at $60^{\circ} \mathrm{C}$, after $48 \mathrm{~h}$ of water immersion; $\mathrm{MS}_{1}$ is the Marshall stability at $60^{\circ} \mathrm{C}$, after $30 \mathrm{~min}$ of water immersion; and $\mathrm{MS}_{0}$ is the residual Marshall stability at $60^{\circ} \mathrm{C}$, after $48 \mathrm{~h}$ of water immersion.

The freeze-thaw splitting strength test is used to evaluate the freeze-thaw performance of the mixture. Two groups of samples are considered in the Marshall method. One group is kept at $20^{\circ} \mathrm{C}$. The other group is kept refrigerated at $18^{\circ} \mathrm{C}$ for $16 \mathrm{~h}$ and then in a water bath at $60^{\circ} \mathrm{C}$ for $24 \mathrm{~h}$. The splitting strength tests were carried out according to the Standard Test Methods of Bitumen and Bituminous Mixtures for Highway Engineering, and the maximum strength values 
TABLE 2: Surface free energy components for the probe liquids $\left(25^{\circ} \mathrm{C}\right)$.

\begin{tabular}{lccccc}
\hline Probe liquids & $\gamma_{l}$ & $\gamma_{l}^{d}$ & $\gamma_{l}^{p}$ & $\gamma_{l}^{p^{+}}$ & $\gamma_{l}^{p^{-}}$ \\
\hline Distilled water & 72.80 & 21.80 & 51.00 & 25.50 & 25.50 \\
\hline Glycerol & 64.00 & 34.00 & 30.00 & 57.40 & 3.92 \\
\hline Formamide & 56.00 & 39.00 & 19.00 & 39.60 & 2.28 \\
\hline
\end{tabular}

were recorded. The freeze-thaw splitting strength ratio is adopted for the analysis, as calculated below:

$$
\mathrm{TSR}=\frac{R_{T 2}}{R_{T 1}} \times 100,
$$

where TSR is the freeze-thaw strength ratio, $\% ; R_{T 1}$ is the maximum strength without freeze and thaw in $\mathrm{MPa} ; R_{T 2}$ is the maximum strength after freeze and thaw in MPa.

2.3. SFE Method. The SFE of a solid (or liquid) is defined as the work required for increasing a unit area of a surface of that solid (or liquid) under vacuum. The total surface energy mainly comprises three independent components, namely, a monopolar acidic component $\left(\gamma^{p^{+}}\right)$, a monopolar basic component $\left(\gamma^{p^{-}}\right)$, and a polar or Lifshitz-van der Waals component $\left(\gamma^{d}\right)[18,19]$. The total SFE $(\gamma)$ can be stated based on the Lifshitz-van der Waals component $\left(\gamma^{d}\right)$ and acid-base component $\left(\gamma^{p}\right)$, as shown in

$$
\gamma=\gamma^{d}+\gamma^{p}
$$

where

$$
\gamma^{p}=2 \sqrt{\gamma^{p^{+}} \gamma^{p^{-}}}
$$

The work of adhesion $\left(W_{a l}\right)$ between an asphalt binder (subscript $a$ ) and probe liquid (subscript $l$ ) can be determined from

$$
\begin{aligned}
W_{a l} & =(1+\cos \theta) \gamma_{l} \\
& =2\left(\sqrt{\gamma_{a}^{d} \gamma_{l}^{d}}+\sqrt{\gamma_{a}^{p^{+}} \gamma_{l}^{p^{-}}}+\sqrt{\gamma_{a}^{p^{-}} \gamma_{l}^{p^{+}}}\right),
\end{aligned}
$$

where $\gamma_{a}^{d}, \gamma_{a}^{p^{+}}$, and $\gamma_{a}^{p^{-}}$represent the SFE components of the asphalt binder; $\gamma_{l}^{d}, \gamma_{l}^{p^{+}}$, and $\gamma_{l}^{p^{-}}$represent the SFE components of the probe liquid; $\theta$ represents the contact angle.

In (5), the SFE components of an asphalt binder are given by the three unknowns $\left(\gamma_{a}^{d}, \gamma_{a}^{p^{+}}\right.$, and $\left.\gamma_{a}^{p^{-}}\right)$. To calculate the SFE of the asphalt binder, it was necessary to measure contact angles with three different probe liquids. The SFE characteristics of these probe liquids $\left(\gamma_{l}^{d}, \gamma_{l}^{p^{+}}\right.$, and $\left.\gamma_{l}^{p^{-}}\right)$ must be known beforehand. Distilled water, glycerol, and formamide were selected as probe liquids because of their relatively large SFE values. Their SFE components are listed in Table 2.

The sessile drop method was used to conduct the SFE in this study and an optical contact angle technique was used

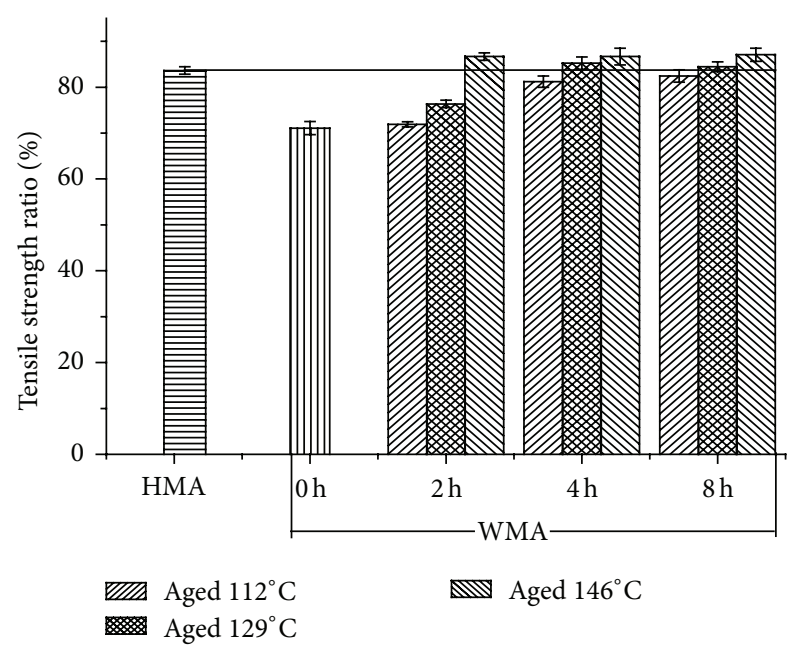

FIGURE 3: Change in the freeze-thaw splitting strength ratios as a function of aging temperature and time.

to measure the contact angles between the asphalt and probe liquids [20]. The asphalt binder samples were prepared by heating at $163^{\circ} \mathrm{C}$ and then pouring a small amount on the plates that had been previously placed on a heater to attain a constant temperature of $60^{\circ} \mathrm{C}$. Then, the plate with the asphalt binder was heated using another heater at $163^{\circ} \mathrm{C}$ for about $5 \mathrm{~min}$, and an even thin film coating was created on the surface of the plate. The sample was then cooled down to room temperature and kept in desiccators for $12 \mathrm{~h}$ at room temperature before testing. The contact angle was measured using the Drop Shape Analyzer 100 (DSA 100), which is composed of an illumination device, a charge-coupled device (CCD) camera, three micro syringes with needles built into the machine, and image analysis software. The measurement was performed at room temperature. Each liquid drop was individually dropped at five different locations of the asphalt film and the contact angles were measured. The average contact angle was recorded.

\section{Results and Discussion}

3.1. Effect of Short-Term Aging on the Freeze-Thaw Splitting Strength Ratios. Figure 3 shows a comparison of the freezethaw splitting strength ratios after the short-term aging with different aging times and temperatures in the laboratory. The freeze-thaw splitting strength ratios of the unaged WMA specimens are clearly lower than those of HMA because the porosity of the unaged WMA specimens is larger when the WMA was prepared at lower compacted temperatures, compared with HMA. This indicates that the moisture susceptibility of the unaged WMA specimens is higher than that of HMA, which would increase the possibility of damage occurring in the unaged WMA specimens in the field.

In terms of the short-term aging process, the freezethaw splitting strength ratios significantly increased with an increase in the aging temperature or time except for higher temperature and longer time. The freeze-thaw splitting strength ratios of WMA strongly depend on the aging time at 
TABLE 3: Statistical analysis results of the freeze-thaw splitting strength ratios of WMA specimens at different aging times and temperatures.

\begin{tabular}{|c|c|c|c|c|c|c|c|c|c|}
\hline & \multicolumn{3}{|c|}{$2 \mathrm{~h}$} & \multicolumn{3}{|c|}{$4 \mathrm{~h}$} & \multicolumn{3}{|c|}{$8 \mathrm{~h}$} \\
\hline & $112^{\circ} \mathrm{C}$ & $129^{\circ} \mathrm{C}$ & $146^{\circ} \mathrm{C}$ & $112^{\circ} \mathrm{C}$ & $129^{\circ} \mathrm{C}$ & $146^{\circ} \mathrm{C}$ & $112^{\circ} \mathrm{C}$ & $129^{\circ} \mathrm{C}$ & $146^{\circ} \mathrm{C}$ \\
\hline \multicolumn{10}{|l|}{$2 \mathrm{~h}$} \\
\hline $112^{\circ} \mathrm{C}$ & - & S & S & S & $S$ & $S$ & $S$ & $S$ & S \\
\hline $129^{\circ} \mathrm{C}$ & - & - & S & S & S & S & S & S & S \\
\hline $146^{\circ} \mathrm{C}$ & - & - & - & S & S & $\mathrm{N}$ & S & S & $\mathrm{N}$ \\
\hline \multicolumn{10}{|l|}{$4 \mathrm{~h}$} \\
\hline $112^{\circ} \mathrm{C}$ & - & - & - & - & $S$ & S & $S$ & S & S \\
\hline $129^{\circ} \mathrm{C}$ & - & - & - & - & - & $S$ & S & $\mathrm{N}$ & $S$ \\
\hline $146^{\circ} \mathrm{C}$ & - & - & - & - & - & - & S & $S$ & $\mathrm{~N}$ \\
\hline \multicolumn{10}{|l|}{$8 \mathrm{~h}$} \\
\hline $112^{\circ} \mathrm{C}$ & - & - & - & - & - & - & - & S & S \\
\hline $129^{\circ} \mathrm{C}$ & - & - & - & - & - & - & - & - & S \\
\hline $146^{\circ} \mathrm{C}$ & - & - & - & - & - & - & - & - & - \\
\hline
\end{tabular}

N: nonsignificant; S: significant.

different temperatures for the aged specimens. For the WMA specimens aged at $112^{\circ} \mathrm{C}$, a general trend was found, where the freeze-thaw splitting strength ratio of WMA aged for $8 \mathrm{~h}$ was the highest and that of WMA aged for $2 \mathrm{~h}$ was the lowest. For the WMA specimens aged at $129^{\circ} \mathrm{C}$, the freezethaw splitting strength ratios of WMA increased before aging for $4 \mathrm{~h}$. However, the freeze-thaw splitting strength ratios do not have any relevant effect for WMA aged at $146^{\circ} \mathrm{C}$. This indicates that the aging time has a dominant effect on the moisture susceptibility of WMA at lower temperatures and this effect is reduced at higher temperatures.

Moreover, although the freeze-thaw splitting strength ratios of WMA specimens aged for $8 \mathrm{~h}$ at $112^{\circ} \mathrm{C}$ are less than that of HMA, the difference is small. For WMA specimens aged for $4 \mathrm{~h}$ at $129^{\circ} \mathrm{C}$ and $2 \mathrm{~h}$ at $146^{\circ} \mathrm{C}$, the freeze-thaw splitting strength ratios are larger than that of HMA. These results indicate that the difference in the moisture susceptibility between WMA and HMA reduces with the short-term aging process. It can thus be concluded that the short-term aging process has significant effect on the moisture susceptibility of WMA. In other words, the use of WMA should undergo a summer of aging in order to avoid the moisture damage in the field.

Two-way analysis of variance was used to evaluate the statistical significance of the change in the freeze-thaw splitting strength ratios of WMA with aging time and temperature, and the results are shown in Table 3. The data indicate that the freeze-thaw splitting strength ratios of WMA are affected significantly by the aging time and temperature. Also, the difference of the freeze-thaw splitting strength ratios of WMA for different aging times and temperatures is statistically significant in most cases. However, there is no significant difference, at $a=0.05$ level, among the freeze-thaw splitting strength ratios of WMA for aging temperature of $146^{\circ} \mathrm{C}$ for $2 \mathrm{~h}, 4 \mathrm{~h}$, and $8 \mathrm{~h}$.

3.2. Effect of Short-Term Aging on the Residual Marshall Stability of WMA. Residual Marshall stability is another index used for evaluating the water stability of an asphalt mixture.

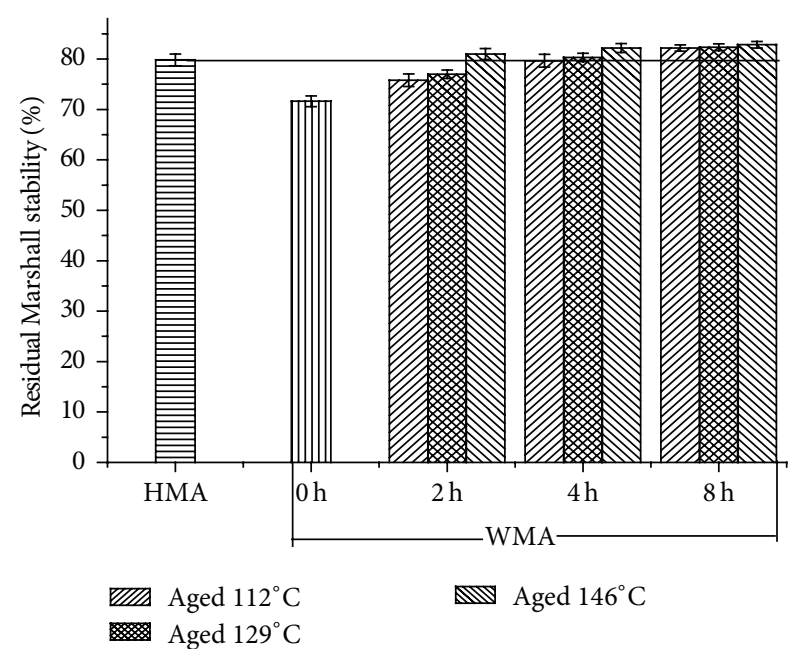

FIGURE 4: Change in the residual Marshall stability as a function of aging temperature and time.

Large residual Marshall stability value indicates good water stability. After the aging process with different aging times and temperatures, the residual Marshall stability of WMA was measured and the results are illustrated in Figure 4. The aging time has a different effect on the residual Marshall stability at different temperatures. The residual Marshall stability of all WMA specimens generally increased with aging time. The increase in the residual Marshall stability is different for different aging temperatures. For WMA specimens aged at $112^{\circ} \mathrm{C}$ and $129^{\circ} \mathrm{C}$, the aging time had a significant effect on the residual Marshall stability. The increase in the residual Marshall stability is the highest (3.7\%) for WMA aged for $4 \mathrm{~h}$, compared with that aged for $2 \mathrm{~h}$ at $112^{\circ} \mathrm{C}$. However, the aging time had no significant effect on the residual Marshall stability of WMA aged at $146^{\circ} \mathrm{C}$. It can thus be concluded that aging time has a more significant effect than aging temperature on the residual Marshall stability of WMA. It can also be found that the increasing trend is not as obvious as that 
TABLE 4: Statistical analysis results of the residual Marshall stability of WMA specimens at different aging times and temperatures.

\begin{tabular}{|c|c|c|c|c|c|c|c|c|c|}
\hline & \multicolumn{3}{|c|}{$2 \mathrm{~h}$} & \multicolumn{3}{|c|}{$4 \mathrm{~h}$} & \multicolumn{3}{|c|}{$8 \mathrm{~h}$} \\
\hline & $112^{\circ} \mathrm{C}$ & $129^{\circ} \mathrm{C}$ & $146^{\circ} \mathrm{C}$ & $112^{\circ} \mathrm{C}$ & $129^{\circ} \mathrm{C}$ & $146^{\circ} \mathrm{C}$ & $112^{\circ} \mathrm{C}$ & $129^{\circ} \mathrm{C}$ & $146^{\circ} \mathrm{C}$ \\
\hline \multicolumn{10}{|l|}{$2 \mathrm{~h}$} \\
\hline $112^{\circ} \mathrm{C}$ & - & $\mathrm{N}$ & S & S & S & S & S & S & $S$ \\
\hline $129^{\circ} \mathrm{C}$ & - & - & $S$ & S & S & $S$ & $S$ & $S$ & $S$ \\
\hline $146^{\circ} \mathrm{C}$ & - & - & - & S & $\mathrm{S}$ & $\mathrm{N}$ & S & S & $\mathrm{N}$ \\
\hline \multicolumn{10}{|l|}{$4 \mathrm{~h}$} \\
\hline $112^{\circ} \mathrm{C}$ & - & - & - & - & $\mathrm{N}$ & S & S & S & S \\
\hline $129^{\circ} \mathrm{C}$ & - & - & - & - & - & $S$ & S & S & S \\
\hline $146^{\circ} \mathrm{C}$ & - & - & - & - & - & - & $S$ & $S$ & $\mathrm{~N}$ \\
\hline \multicolumn{10}{|l|}{$8 \mathrm{~h}$} \\
\hline $112^{\circ} \mathrm{C}$ & - & - & - & - & - & - & - & $\mathrm{N}$ & $\mathrm{N}$ \\
\hline $129^{\circ} \mathrm{C}$ & - & - & - & - & - & - & - & - & $\mathrm{N}$ \\
\hline $146^{\circ} \mathrm{C}$ & - & - & - & - & - & - & - & - & - \\
\hline
\end{tabular}

$\mathrm{N}$ : nonsignificant; S: significant.

of the freeze-thaw splitting strength ratios. This indicates that the freeze-thaw splitting strength ratio is a more important index for evaluating the moisture susceptibility of WMA after aging.

It must be noted that the residual Marshall stability of the unaged WMA specimens is lower than that of HMA. However, the residual Marshall stability of the WMA specimens is larger than that of HMA after aging for $8 \mathrm{~h}$ at $112^{\circ} \mathrm{C}, 8 \mathrm{~h}$ at $129^{\circ} \mathrm{C}$, and $2 \mathrm{~h}$ at $146^{\circ} \mathrm{C}$. It also can be concluded that the moisture susceptibility of WMA is similar to or even larger than that of HMA after short-term aging. In practical use, WMA should thus undergo a summer of aging in order to avoid moisture damage in the field.

The statistical significance of the change in residual Marshall stability of WMA with respect to aging time and temperature was examined (Table 4 ). The statistical results show that the residual Marshall stability of the WMA mixtures was significantly different under different aging times and temperatures, except for some aging conditions. There was no significant difference, at $a=0.05$ level, among the residual Marshall stability values of WMA aged at $146^{\circ} \mathrm{C}$ for $2 \mathrm{~h}, 4 \mathrm{~h}$, and $8 \mathrm{~h}$. Moreover, the difference in the residual Marshall stability of WMA between aging temperatures of $112^{\circ} \mathrm{C}, 129^{\circ} \mathrm{C}$, and $146^{\circ} \mathrm{C}$ for $8 \mathrm{~h}$ was not statistically significant in most cases at the $5 \%$ level.

3.3. Effect of Aging Conditions on the SFE of WMA. The average value $(\mathrm{Av})$ and the coefficient of variation $(\mathrm{Cv})$ of the contact angles for different asphalt binders were measured with the three probe liquids, and the results are listed in Table 5. A method developed by Kwok and Neumann was used in this study to assess the validity of the contact angle result [21]. This method specifies that a linear relationship exists between $\gamma$ and $\gamma \cos \theta$ for a given solid with various liquids. A great value of the determination coefficient $\left(R^{2}\right.$, ranging from 0 to 1 ) of the resulting curve indicates the validity of the contact angle measurements. In this study, $R^{2}$ varied from 0.953 to 0.997 , which indicates that the contact angle results meet the aforementioned criteria.

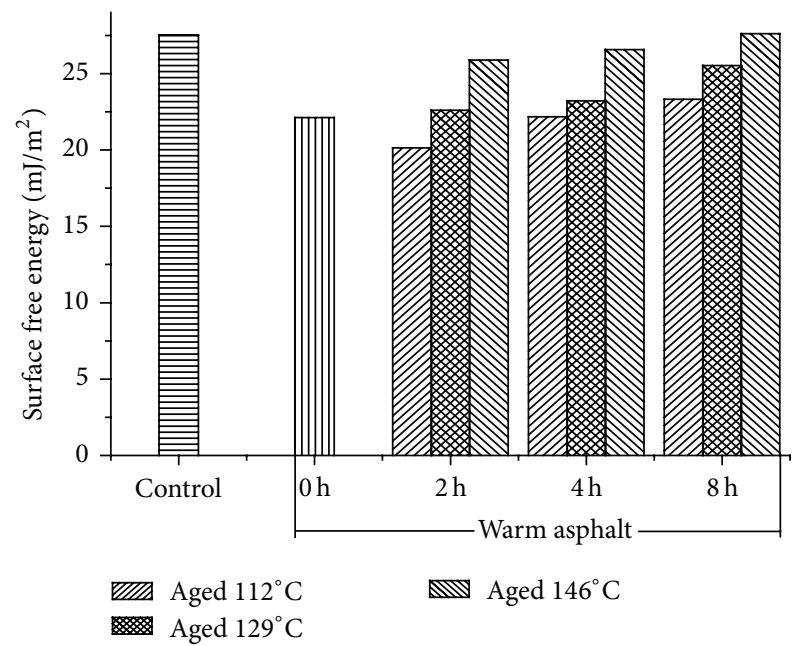

FIgURE 5: Change in SFE as a function of aging temperature and time.

The total SFE of different asphalt samples were calculated from the measured contact angles using (5). Figure 5 shows the SFE of different WMA samples aged at different aging times and temperatures with respect to the contact angles. The SFE of the WMA specimens are clearly lower than that of HMA, except for the WMA specimen aged for $8 \mathrm{~h}$ at $146^{\circ} \mathrm{C}$. This indicates that Sasobit reduced the cohesive force of the WMA asphalt binder. This is primarily because Sasobit is a crystalline, long-chain aliphatic polymethylene hydrocarbon produced from natural gas by using the Fischer-Tropsch (FT) process, which makes it hydrophobic [22]. Therefore, Sasobit can decrease the SFE. However, the total SFE of the WMA specimens increased with the increasing aging times or temperatures. These results seem to contradict the conclusion that the SFE of asphalt binder decreased with increasing aging time and temperature in some reports [23]. This indicates that short-term aging enhances the moisture stability by improving the cohesive force of WMA asphalt binder. 
TABLE 5: Average contact angles of RTFO aged asphalt binders with WMA additives $\left(22^{\circ} \mathrm{C}\right)$.

\begin{tabular}{|c|c|c|c|c|c|c|c|}
\hline \multirow{2}{*}{ Aging time } & \multirow{2}{*}{ Aging temperature $\left({ }^{\circ} \mathrm{C}\right)$} & \multicolumn{2}{|c|}{ Distilled water } & \multicolumn{2}{|c|}{ Glycerol } & \multicolumn{2}{|c|}{ Formamide } \\
\hline & & $\operatorname{Av}\left({ }^{\circ}\right)$ & $\mathrm{Cv}$ & $\operatorname{Av}\left({ }^{\circ}\right)$ & $\mathrm{Cv}$ & $\operatorname{Av}\left({ }^{\circ}\right)$ & $\mathrm{Cv}$ \\
\hline $0 \mathrm{~h}$ & $\mathrm{~N}$ & 107.3 & 0.009 & 90.8 & 0.0106 & 103.5 & 0.026 \\
\hline \multirow{3}{*}{$2 \mathrm{~h}$} & 112 & 107.8 & 0.019 & 89.0 & 0.0092 & 100.8 & 0.010 \\
\hline & 129 & 106.5 & 0.012 & 88.3 & 0.0194 & 101.0 & 0.008 \\
\hline & 146 & 106.8 & 0.021 & 85.0 & 0.0288 & 99.0 & 0.025 \\
\hline \multirow{3}{*}{$4 \mathrm{~h}$} & 112 & 110.0 & 0.020 & 87.5 & 0.0148 & 100.3 & 0.017 \\
\hline & 129 & 109.3 & 0.016 & 86.0 & 0.0095 & 99.0 & 0.008 \\
\hline & 146 & 107.0 & 0.017 & 84.3 & 0.0114 & 98.5 & 0.021 \\
\hline \multirow{3}{*}{$8 \mathrm{~h}$} & 112 & 109.0 & 0.020 & 85.8 & 0.0112 & 98.8 & 0.005 \\
\hline & 129 & 106.3 & 0.009 & 84.3 & 0.0114 & 98.0 & 0.014 \\
\hline & 146 & 106.5 & 0.020 & 82.0 & 0.0100 & 96.5 & 0.013 \\
\hline
\end{tabular}

As seen in Figure 5, the SFE of WMA asphalt binder specimens increased with the aging temperature for all aging times $(2 \mathrm{~h}, 4 \mathrm{~h}$, and $8 \mathrm{~h})$. The increase in SFE is larger when the aging temperature varied from $129^{\circ} \mathrm{C}$ to $146^{\circ} \mathrm{C}$ for all aging times. The increase in SFE is the lowest when the aging temperature varied from $112^{\circ} \mathrm{C}$ to $129^{\circ} \mathrm{C}$ for $4 \mathrm{~h}$ of aging. In addition, the SFE of WMA asphalt binder specimens increased with aging time for aging temperature of $112^{\circ} \mathrm{C}$. The increase in SFE is not significant as the aging time increased for WMA asphalt mixture aged at higher temperatures $\left(146^{\circ} \mathrm{C}\right)$. The increase in SFE of WMA asphalt binder specimens during the early aging stage ( $2 \mathrm{~h}$ to $4 \mathrm{~h})$ is larger than that during the later aging stage ( $4 \mathrm{~h}$ to $8 \mathrm{~h}$ ). It can also be concluded that the aging temperature has a more significant effect than aging time on the SFE of WMA asphalt binder.

\section{Summary and Conclusions}

The effects of short-term aging on the moisture susceptibility of asphalt mixtures containing Sasobit warm mix additive were investigated using immersed Marshall test and freezethaw splitting test. The effects of the short-term aging process on the SFE of asphalt binder extracted from WMA mixtures were investigated by the sessile drop method. These results led to the following conclusions:

(1) The moisture susceptibility of the unaged WMA specimens is larger than that of HMA, which increased the possibility of moisture damage to the unaged WMA specimens in the field.

(2) Based on the general trend of increase in the freezethaw splitting strength ratios and the residual Marshall stability, the aging time and temperature were found to have a significant effect on the improvement of moisture susceptibility of asphalt mixtures containing Sasobit warm mix additive.

(3) The aging time has a dominant effect on the moisture susceptibility of WMA at lower temperatures, and this effect is reduced at higher temperatures.
(4) The moisture susceptibility of asphalt mixtures containing Sasobit warm mix additive can be similar to that of HMA after aging for a certain time and temperature. It is recommended that the moisture susceptibility of asphalt mixtures containing Sasobit warm mix additive be tested after the short-term aging for $2 \mathrm{~h}$ at $146^{\circ} \mathrm{C}$.

(5) The SFE of asphalt binders extracted from Sasobit warm mix is lower than that of HMA. However, the aging time and temperature significantly affect the SFE of asphalt binders extracted from Sasobit warm mix. The SFE of the asphalt binders increased with the aging time and temperature.

(6) WMA should undergo a summer of aging in order to avoid moisture damage in the field.

\section{Conflict of Interests}

The authors declare that there is no conflict of interests regarding the publication of this paper.

\section{Acknowledgments}

The research work reported in this paper was supported by the National Natural Science Foundation of China (Grants nos. 51408287, 51568037), Program for Changjiang Scholars and Innovative Research Team in University (IRT1139), Natural Science Foundation of Gansu Province (1506RJZA064), Fundamental Research Funds for the Central Universities (2013G1502025), Gansu DOT Research Project (2010-12), Young Scholars Science Foundation of Lanzhou Jiaotong University (2011031), and Science and Technology Support Foundation of Lanzhou Jiaotong University (ZC2012004).

\section{References}

[1] H. Malladi, D. Ayyala, A. A. Tayebali, and N. P. Khosla, "Laboratory evaluation of warm-mix asphalt mixtures for moisture and rutting susceptibility," Journal of Materials in Civil Engineering, vol. 27, no. 5, Article ID 04014162, 2015. 
[2] S. D. Capitão, L. G. Picado-Santos, and F. Martinho, "Pavement engineering materials: review on the use of warm-mix asphalt," Construction and Building Materials, vol. 36, pp. 1016-1024, 2012.

[3] G. C. Hurley and B. D. Prowell, "Evaluation of Sasobit for use in warm mix asphalt," NCAT Report 05-06, National Center for Asphalt Technology, Auburn University, Auburn, Ala, USA, 2005.

[4] J. Liu, S. Saboundjian, P. Li, B. Connor, and B. Brunette, "Laboratory evaluation of sasobit-modified warm-mix asphalt for alaskan conditions," Journal of Materials in Civil Engineering, vol. 23, no. 11, pp. 1498-1505, 2011.

[5] P. Guo, "Study on water stability of Sasobit warm mixture asphalt," Journal of Zhengzhou University (Engineering Science), vol. 31, no. 5, pp. 36-39, 2010.

[6] J. Ji, J. Ran, and S.-F. Xu, "Road performances of Sasobit asphalt mixture," Journal of Traffic and Transportation Engineering, vol. 9, no. 4, pp. 6-9, 2009.

[7] R. Zhang and X.-M. Huang, "Performance analysis of asphalt and asphalt mixture with Sasobit," Journal of Traffic and Transportation Engineering, vol. 7, no. 4, pp. 54-57, 2007.

[8] X.-P. Ji and Y.-L. Sun, "Experimental research of warm mix asphalt with Sasobit," Journal of Wuhan University of Technology, vol. 32, no. 14, pp. 75-78, 2010.

[9] A. Buddhala, Z. Hossain, N. M. Wasiuddin, M. Zaman, and E. A. O'Rear, "Effects of an amine anti-stripping agent on moisture susceptibility of sasobit and aspha-min mixes by surface free energy analysis," Journal of Testing and Evaluation, vol. 40, no. $1,2012$.

[10] N. M. Wasiuddin, M. M. Zaman, and E. A. O’Rear, "Effect of sasobit and Aspha-Min on wettability and adhesion between asphalt binders and aggregates," Transportation Research Record, vol. 2051, pp. 80-89, 2008.

[11] R. Ghabchi, D. Singh, M. Zaman, and Q. Tian, "Mechanistic evaluation of the effect of WMA additives on wettability and moisture susceptibility properties of asphalt mixes," Journal of Testing and Evaluation, vol. 41, no. 6, 2013.

[12] E. M. Amy, A. Edith, Y. Fan et al., Evaluation of the Moisture Susceptibility of WMA Technologies, Texas A\&M Transportation Institute, 2014.

[13] T. Gandhi, W. Rogers, and S. Amirkhanian, "Laboratory evaluation of warm mix asphalt ageing characteristics," International Journal of Pavement Engineering, vol. 11, no. 2, pp. 133-142, 2010.

[14] H. Zelelew, C. Paugh, M. Corrigan, S. Belagutti, and J. Ramakrishnareddy, "Laboratory evaluation of the mechanical properties of plant-produced warm-mix asphalt mixtures," Road Materials and Pavement Design, vol. 14, no. 1, pp. 49-70, 2013.

[15] S. Sargand, M. D. Nazzal, A. Al-Rawashdeh, and D. Powers, "Field evaluation of warm-mix asphalt technologies," Journal of Materials in Civil Engineering, vol. 24, no. 11, pp. 1343-1349, 2012.

[16] W. Mogawer, A. Austerman, and H. Bahia, "Evaluating the effect of warm-mix asphalt technologies on moisture characteristics of asphalt binders and mixtures," Transportation Research Record, vol. 2209, pp. 52-60, 2011.

[17] T. Butz, I. Rahimian, and G. Hildebrand, "Modification of road bitumens with the fischer-tropsch paraffin Sasobit," Journal of Applied Asphalt Binder Technology, vol. 1, no. 2, pp. 70-86, 2001.

[18] Y. Tan and M. Guo, "Using surface free energy method to study the cohesion and adhesion of asphalt mastic," Construction and Building Materials, vol. 47, pp. 254-260, 2013.
[19] R. Ghabchi, D. Singh, and M. Zaman, "Evaluation of moisture susceptibility of asphalt mixes containing RAP and different types of aggregates and asphalt binders using the surface free energy method," Construction and Building Materials, vol. 73, pp. 479-489, 2014.

[20] J.-M. Wei, Y.-Z. Zhang, and Y.-S. John, "Determination of the surface free energy of asphalt binders by sessile drop method," Acta Petrolei Sinica: Petroleum Processing Section, vol. 25, no. 2, pp. 207-215, 2009.

[21] D. Y. Kwok and A. W. Neumann, "Contact angle measurement and contact angle interpretation," Advances in Colloid and Interface Science, vol. 81, no. 3, pp. 167-249, 1999.

[22] A. Jamshidi, M. O. Hamzah, and Z. You, "Performance of warm mix asphalt containing aasobit: state-of-the-art," Construction and Building Materials, vol. 38, pp. 530-553, 2013.

[23] J. Wei and Y. Zhang, "Influence of aging on surface free energy of asphalt binder," International Journal of Pavement Research and Technology, vol. 3, no. 6, pp. 343-351, 2010. 

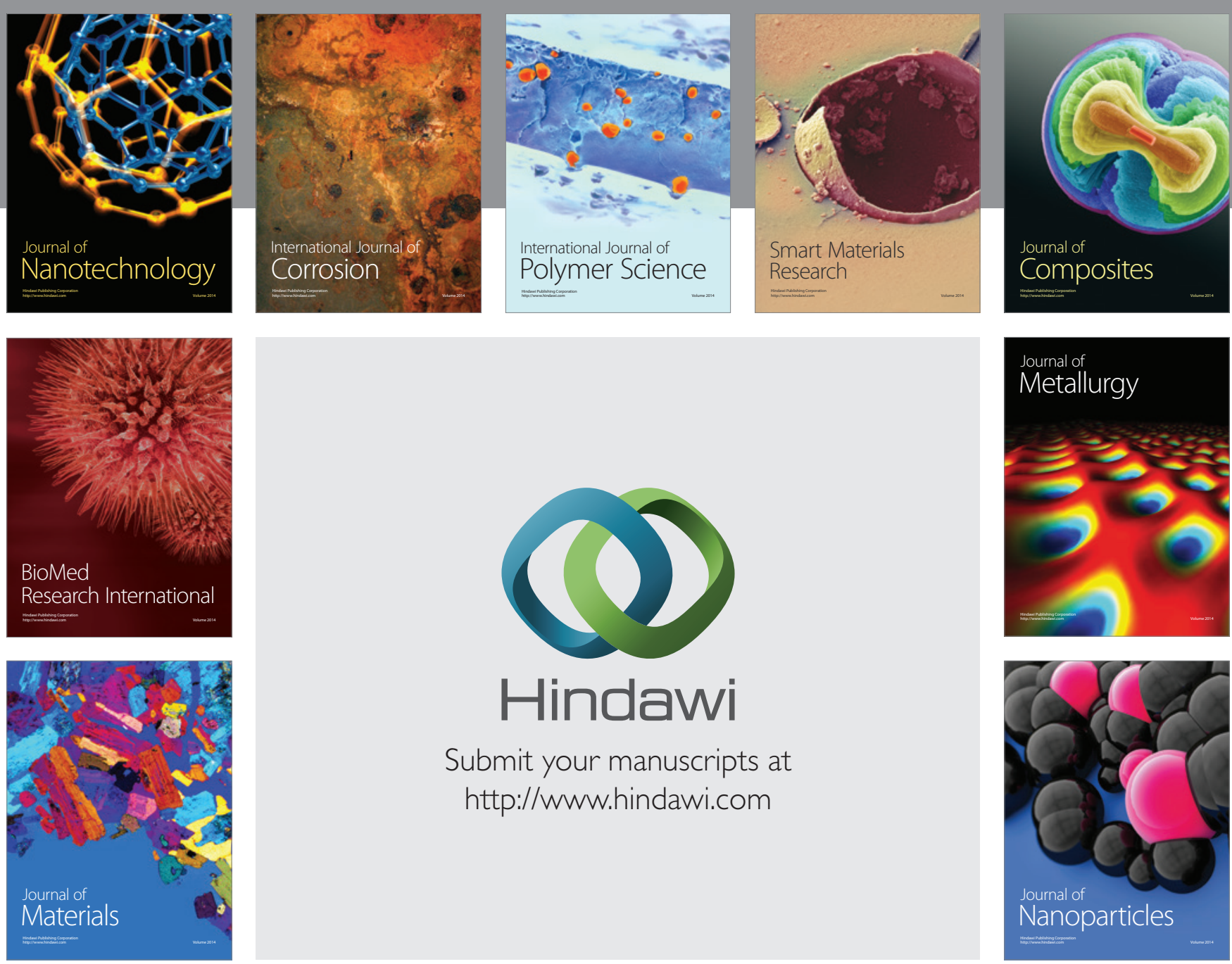

Submit your manuscripts at http://www.hindawi.com
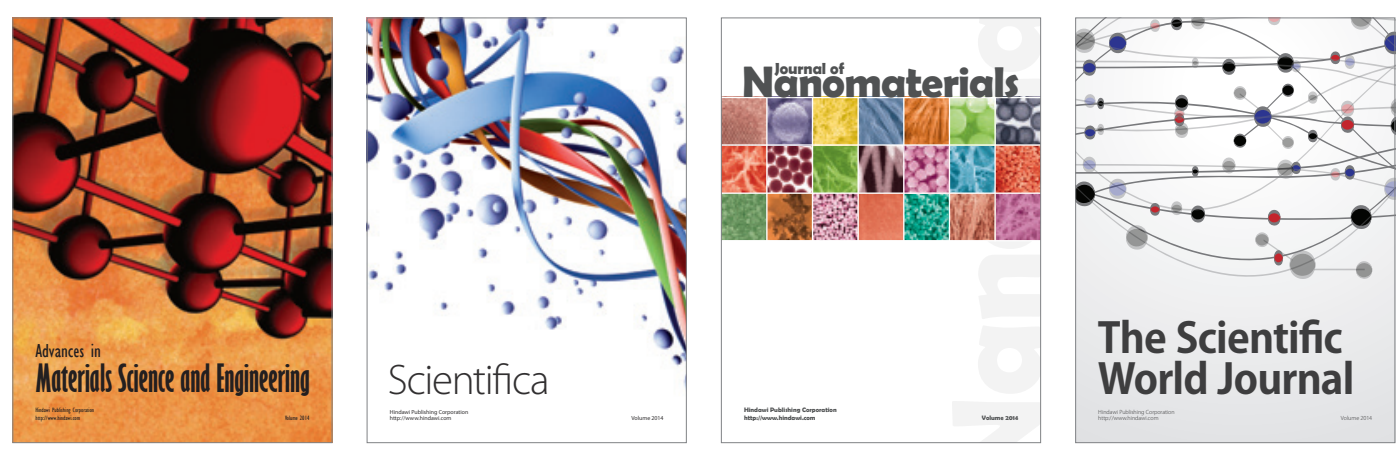

\section{The Scientific World Journal}
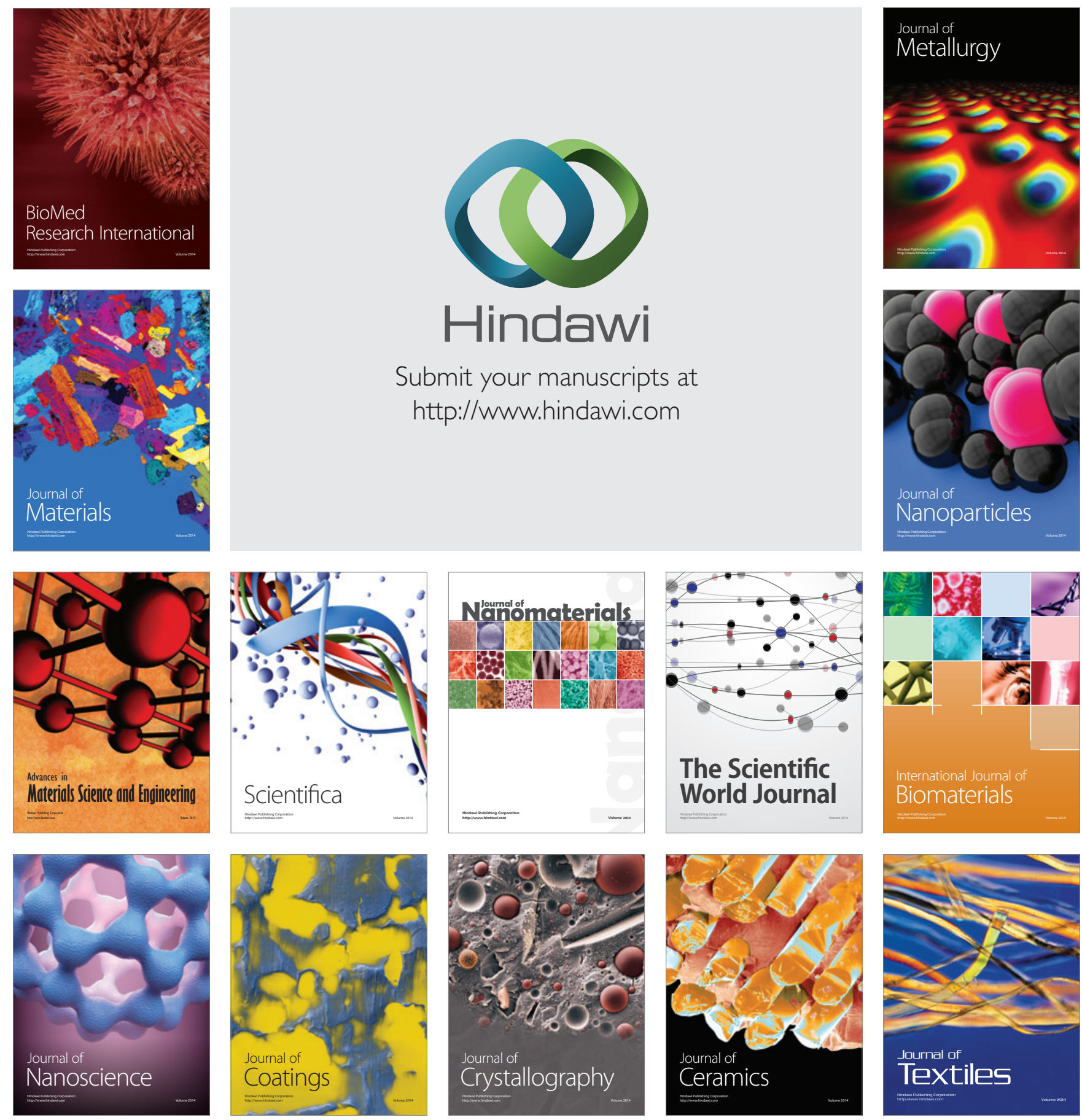